\title{
Pharmacokinetics of quinine in chronic liver disease
}

\author{
P. AUPRAYOON ${ }^{1}$, K. SUKONTASON ${ }^{2}$, K. NA-BANGCHANG ${ }^{2}$, V. BANMAIRUROI ${ }^{2}$, P. MOLUNTO $^{2} \&$ \\ J. KARBWANG ${ }^{2}$ \\ ${ }^{1}$ Department of Medicine, Prapokklao Hospital, Chantaburi Province, Thailand \\ ${ }^{2}$ Clinical Pharmacology Unit, Faculty of Tropical Medicine, Mahidol University, Bangkok, Thailand
}

The pharmacokinetics of quinine were investigated in a) six healthy male Thai subjects, and b) nine male Thai patients with a moderate degree of chronic liver disease, after a single oral dose of $600 \mathrm{mg}$ quinine sulphate. $t_{\max }$ and $t_{1 / 2,2}$ were significantly prolonged in patients (median [range] $t_{\max } 2$ [1-5] vs $1.6[0.8-2] \mathrm{h}$; $t_{1 / 2, \mathrm{z}} 23.4[17.4-41.7]$ vs $\left.9.7[7.8-17.2] \mathrm{h}\right)$, and $V_{\mathrm{z}} / \mathrm{F}$ was significantly larger (median [range] 4.21 [2.33-15.87] vs 2.78 [1.49-3.38] $1 \mathrm{~kg}^{-1}$ ). Median (range) concentration of the plasma unbound Qn fraction collected from the patients at $4 \mathrm{~h}$ after drug administration was $17(8.4-17.8) \%$ of total drug concentration.

\section{Keywords quinine pharmacokinetics chronic liver disease}

\section{Introduction}

Quinine is an effective antimalarial for the treatment of chloroquine-resistant falciparum malaria and is the drug of choice for the treatment of severe malaria [1]. It is extensively metabolized by hepatic microsomal enzymes to the hydroxy and $N$-oxide products [2] and elimination of quinine by metabolism accounts for approximately $80 \%$ of its systemic clearance [3].

In previous studies, the clearance of quinine was shown to be significantly reduced in patients during the acute phase of hepatitis-B infection [4] and in severe malaria [5]. Hepatic dysfunction during these acute phase infections may be responsible for the changes. In chronic liver disease, irreversible pathological changes of liver parenchyma and function occur [6], and clearance of some drugs, e.g. propranolol, clotiazepam, digitoxin, and metoclopramide has been shown to be markedly reduced [7-9]. Patients with chronic liver disease, who live in areas where malaria is endemic may require treatment with quinine. In such patients, toxicity could occur due to the accumulation of quinine during multiple dosing. We have carried out a comparative pharmacokinetic study of quinine in patients with chronic liver disease and healthy subjects.

\section{Methods}

Subjects

Nine male Thai patients with chronic liver disease, aged between 37 and 54 years, and weighing 44 to $63 \mathrm{~kg}$ were recruited into the study. Chronic liver disease was diagnosed by clinical and pathological findings verified by ultrasonography, with total bilirubin of more than $2 \mathrm{mg} \mathrm{dl}^{-1}$, prolonged prothrombin (PT) and partial thrombin time (PTT), and reversed albumin/globulin ratio. The severity of the disease in this group of patients was classified as moderate chronic liver disease with grade B of Child's classification [10]. Patients with a history of renal disease were excluded from the study. Patients were admitted to Prapokklao Hospital, Chantaburi province, for at least 7 days. The study was approved by the Ethics Committee of the Ministry of Public Health, Thailand, and written informed consent obtained from each subject.

Prior to and during the study period, no other drugs except vitamin B-complex were prescribed to the patients for supportive therapy. The drug was given as one tablet three times daily (Government Pharmaceutical Organization of Thailand; 1 tablet contains $3 \mathrm{mg}$ vitamin $B_{1}, 2 \mathrm{mg}$ vitamin $B_{2}, 0.25 \mathrm{mg}$ vitamin $B_{6}, 100 \mathrm{mg}$ vitamin $B_{12}, 10 \mathrm{mg}$ niacinamide, and $140 \mathrm{mg}$ dried yeast). Coffee, tobacco and alcoholic drink intake were not allowed prior to and during the investigation period.

Six healthy male Thai subjects, aged between 25 and 49 years, and weighing 46 to $59 \mathrm{~kg}$, with no history of liver or kidney diseases were recruited into this study. Written informed consent for participation to the study was obtained from each subject. They were admitted to the Bangkok Hospital for Tropical Diseases for 7 days. No other drugs, including coffee, tobacco and alcoholic drink intake were allowed prior to and during the investigation period. 


\section{Treatment and blood collection}

Prior to drug administration, all subjects had a physical examination, evaluation of vital signs, a 12-lead electrocardiogram (ECG) and routine blood examinations (haematology, clinical chemistry) and urinalysis.

All subjects were given a single oral dose of $600 \mathrm{mg}$ quinine sulphate $(300 \mathrm{mg} /$ tablet; Government Pharmaceutical Organization of Thailand). The tablets were administered with a glass of water under supervision following an overnight fast. Subjects were allowed to take a meal $2 \mathrm{~h}$ after drug administration. A total of 24 blood samples $(4 \mathrm{ml}$ each) for the assay of quinine were collected from an antecubital vein through an indwelling intravenous Teflon catheter prior to dosage and at $0.25,0.5,0.75,1,1.25,1.5,2,3,4,6,8,10,12,16$, 20, 24, 36, $48 \mathrm{~h}$, and 3, 4, 5, 6, 7 days. Blood samples were collected into heparinized plastic tubes and immediately centrifuged at $1200 \mathrm{~g}$ for $10 \mathrm{~min}$. Plasma was transferred to plastic tubes and stored at $-70^{\circ} \mathrm{C}$ until analysis.

\section{Adverse effects}

All adverse reactions occurring after drug administration were monitored by daily questionnaires for 7 days. These included gastrointestinal, central nervous, cardiovascular, dermatological and haematological systems.

Vital signs (blood pressure, heart rate), and an ECG were recorded at intervals during blood sampling and daily until day 7 .

\section{Drug analysis}

Quinine concentrations in plasma were analysed by h.p.l.c. [11]. The lower limit of detection of quinine in plasma was $4 \mathrm{ng} \mathrm{ml}^{-1}$ using a $0.25 \mathrm{ml}$ specimen. The interassay coefficients of variation were $6.8,1$, and $2 \%$ at concentrations of $0.1,1$, and $5 \mu \mathrm{g} \mathrm{ml}^{-1}$, respectively. Concentrations of the unbound quinine fraction were determined in plasma samples collected from all patients at $4 \mathrm{~h}$ after drug administration. Proteins were first removed from $1 \mathrm{ml}$ plasma samples by ultracentrifugation at $2500 \mathrm{~g}\left(25^{\circ} \mathrm{C}\right)$ for $15 \mathrm{~min}$, using the Amicron YMT system (Amicron Corporation, Denver, Massachussets, USA) [12]. Quinine concentrations in a plasma protein-free untrafiltrate were then measured by h.p.l.c., using the same method as that described for total quinine concentrations.

\section{Pharmacokinetic and statistical analysis}

Pharmacokinetic parameters of quinine in both groups were analysed by model-independent method [13]. Maximum plasma concentration $\left(C_{\max }\right)$ and the time to $C_{\max }\left(t_{\max }\right)$ were noted directly from the concentrationtime data. The terminal elimination half-life $\left(t_{1 / 2, z}\right)$ was calculated from at least five plasma drug concentration values. Total area under the curve (AUC) was calculated using the linear trapezoidal rule with extrapolation to infinity. The residual areas were always less than $5 \%$ of the total AUC values. Mean residence time (MRT) was calculated from the proportion of the area under the concentration * time versus time curve (AUMC) and
AUC. Apparent oral clearance $(\mathrm{CL} / F)$ was estimated from dose/AUC, and the apparent volume of distribution $\left(V_{z} / F\right)$ was calculated according to the relationship; $V_{\mathrm{z}} / F=\mathrm{CL} / F^{*} t_{1 / 2, \mathrm{z}} / 0.693$.

Comparison of the pharmacokinetic parameters obtained from patients with chronic liver disease and those from healthy subjects was made by the MannWhitney $U$-test at a significance level of $P=0.05$. The correlation between total quinine clearance vs serum albumin and bilirubin concentrations was determined using the Spearman Ranks' coefficient of correlation at a significance level of $P=0.05$.

\section{Results}

The patients with chronic liver disease included in the study did not differ from the control subjects in age or weight. Concentrations of serum albumin, globulin, alkaline phosphatase, SGOT, SGPT, total and direct bilirubin were $2.7(2.2-3.3) \mathrm{g} \mathrm{dl}^{-1}, 4.1(3.1-4.8) \mathrm{g} \mathrm{dl}^{-1}$, 34 (17-49) IU, 39 (15-45) IU, 19 (11-33) IU, 1.43 $(0.38-2.32) \mathrm{mg} \mathrm{dl}^{-1}$ and $0.72(0.09-1.23) \mathrm{mg} \mathrm{dl}^{-1}$, respectively (presented as median and range values). None of the patients had signs of renal impairment as supported by the normal levels of serum creatinine and BUN (median [range] values of 1.4 [0.4-1.6] mg dl${ }^{-1}$ and $15[11-20] \mathrm{mg} \mathrm{dl}^{-1}$ ). All of the patients had signs of chronic liver disease and prolongation of PT and PTT (median and range values for test vs control, PT: 15 [13.4-16.9] vs 12.4 [12.4-13.9] s; PTT: 38.4 [34.9-47.4] vs 30 [29.8-31.4] s). All of the patients were conscious. Eight patients had a history of chronic alcoholic consumption, and oedema. The minority had a history of hepatitis (two cases), UGI haemorrhage (three cases), peritonitis (one case), and HBs-antigen positive (three cases). Oedema, ascites, pale, superficial vein dilatation and splenomegaly were common manifestations. Others included spider nevi, hepatomegaly and parotid gland enlargement.

All of the healthy subjects had normal hepatic and renal function as indicated by the results of laboratory tests (median [range] values of serum albumin, globulin, alkaline phosphatase, SGOT, SGPT, total and direct bilirubin were $3.8[3.2-3.9] \mathrm{mg} \mathrm{dl}^{-1}, 3.5$ [2.9-4.2] mg $\mathrm{dl}^{-1}, 30[18-38] \mathrm{iu}, 31[20-42] \mathrm{iu}, 36[17-33] \mathrm{iu}$, $0.69[0.35-0.85] \mathrm{mg} \mathrm{dl} l^{-1}, 0.14[0.01-0.2] \mathrm{mg} \mathrm{dl}^{-1}$, respectively).

\section{Adverse effects}

Quinine sulphate at a single oral dose of $600 \mathrm{mg}$ was well tolerated by both groups of subjects. Mild and selflimiting adverse effects (nausea, headache, tinnitus) were noted during the first 2 days of treatment. No significant prolongation of $\mathrm{Qt}_{\mathrm{c}}$ interval (more than $25 \%$ of baseline) was recorded in either group of subjects.

\section{Pharmacokinetics}

Median plots of plasma concentration vs time for quinine in patients with chronic liver disease and in healthy subjects are shown in Figure 1, and median 


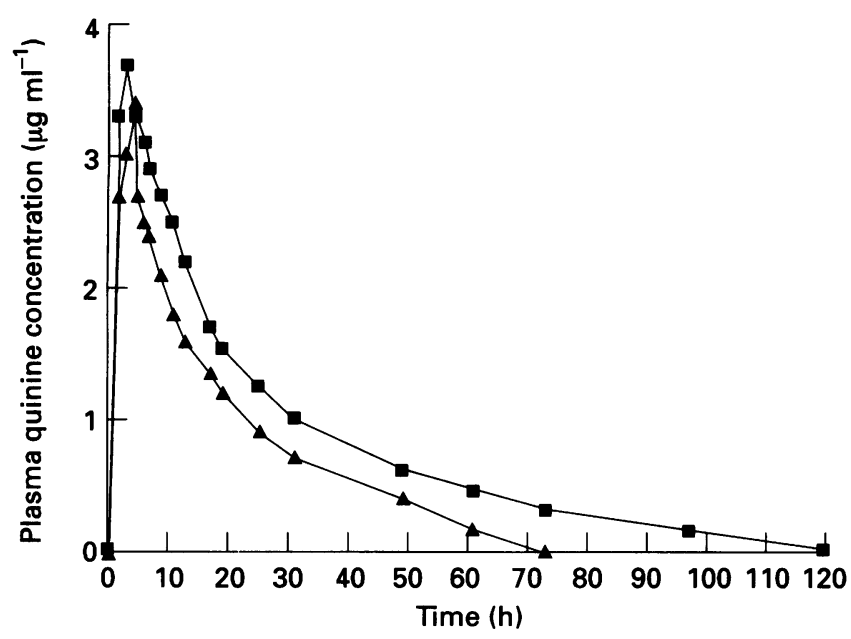

Figure 1 Median plots of plasma concentrations of quinine after a single oral dose of $600 \mathrm{mg}$ in patients with chronic liver disease $(n=9, \square)$ and healthy subjects $(n=6, \Delta)$.

(range) pharmacokinetic parameters are summarized in Table 1.

In comparison with healthy subjects, there were three significant changes in the pharmacokinetics of quinine in patients with moderate chronic liver disease. $t_{\max }$ and $t_{1 / 2, \mathrm{z}}$ were significantly prolonged $\left(t_{\max }: 2\right.$ [1-5] vs 1.6 [0.8-2] h; $t_{1 / 2, z} 23.4$ [17.4-41.7] vs 9.7 [7.8-17.2] h], and $V_{\mathrm{z}} / F$ was significantly larger $(4.21[2.33-15.87] \mathrm{vs}$ $\left.2.78[1.49-3.38] \mathrm{ml} \mathrm{min}^{-1} \mathrm{~kg}^{-1}\right)$.

Median (range) concentrations of the plasma unbound quinine fraction collected from patients at $4 \mathrm{~h}$ after drug administration was $17 \%(8.4-17.8) \%$ of the total concentrations. The ultrafiltrate contained less than $0.1 \%$ protein. It was clear and yellow in all samples.

There was no significant correlation between serum albumin or bilirubin concentrations and the total clearance of quinine $(P=0.1)$.

\section{Discussion}

The pharmacokinetics of oral quinine in patients with moderate chronic liver disease are altered. The prolonged time to maximum concentration of drug in plasma indicates that the rate of absorption is slower in patients than in healthy subjects. In addition, a prolonged terminal phase elimination half-life, expanded apparent volume of distribution, and increased fraction of plasma unbound quinine (median values in normal vs chronic liver disease: 10 [12] vs $17 \%$ ) were observed. In contrast to a previous study in patients during acute phase hepatitis-B infection in which total clearance of intravenous quinine was significantly reduced [4], no change in the total clearance of the drug was found in this group of patients.

Quinine is eliminated largely (80\%) through hepatic metabolism [3], and thus in chronic liver disease where reduced enzyme activity and hepatic blood flow may occur $[7-9,14]$, the impairment of quinine metabolism could be anticipated. However, quinine is a low hepatic extraction drug [15] which is binding-sensitive and therefore the present changes are likely to result from an alteration in enzyme activity and plasma protein binding of the drug. In plasma, quinine binds to protein, principally to $\alpha_{1}$-acid glycoprotein (AAG), although approximately $30 \%$ binds to albumin [16]. Changes in this acute phase reactant concentrations, and parallel changes in the plasma binding of basic drugs have been reported in several conditions, for example, inflammation, malignancy, stress, nephrotic syndrome, malnutrition and hepatic diseases [17-18]. Interestingly, in contrast with acute hepatitis-B infection in which plasma unbound quinine fractions remain unchanged (approximately 10\%) [4], it was found in this study that this fraction was elevated in moderate chronic liver disease (median of $17 \%$ ). Lower levels of serum AAG and albumin due to hepatic dysfunction may be the explanation for the higher portion of the unbound quinine observed [19-21]. Biochemical indices of the disease (serum albumin, bilirubin concentrations) did not correlate with total quinine clearance.

Changes in the oral bioavailability of quinine in chronic liver disease cannot also be excluded as an important contributory factor to the change in quinine disposition. Oral bioavailability of quinine in healthy subjects has been reported to be approximately $80 \%$ [22].

$Q \mathrm{t}_{\mathrm{c}}$ prolongation is one of the most concerning toxicities of quinine [23]. This effect is concentrationdependent and a prolongation of more than $25 \%$ above baseline has been shown to be associated with cardiac arrhthymia [24-25]. However, there was no significant change in $\mathrm{Qt}_{\mathrm{c}}$ interval in the patients in this study despite the higher plasma quinine concentrations.

Table 1 Pharmacokinetic parameters of quinine [median (range)] in patients with chronic liver disease and healthy subjects

\begin{tabular}{lccc}
\hline & $\begin{array}{c}\text { Chronic liver disease } \\
(\mathrm{n}=9)\end{array}$ & $\begin{array}{c}\text { Healthy } \\
(\mathrm{n}=6)\end{array}$ & $\begin{array}{c}95 \% \text { CI of } \\
\text { difference }\end{array}$ \\
\hline$C_{\max }\left(\mu \mathrm{g} \mathrm{ml}^{-1}\right)$ & $3.74(1.22-4.47)$ & $3.45(2.25-3.91)$ & $-1-0.85$ \\
$t_{\max }(\mathrm{h})^{\mathrm{a}}$ & $2(1-5)$ & $1.6(0.8-2)$ & $-3--0.23$ \\
$t_{1 / 2, \mathrm{z}}(\mathrm{h})^{\mathrm{b}}$ & $23.4(17.4-41.7)$ & $9.7(7.8-17.2)$ & $19--7.67$ \\
$\mathrm{AUC}\left(\mu \mathrm{g} \mathrm{min} \mathrm{ml}^{-1}\right)$ & $95.9(29-138)$ & $61.8(41.9-86.5)$ & $-54.5-12.3$ \\
$\mathrm{CL} / F\left(\mathrm{ml} \mathrm{min}^{-1} \mathrm{~kg}^{-1}\right)$ & $2.31(1.21-7.64)$ & $2.84(1.63-3.98)$ & $-1.54-1.57$ \\
$V_{\mathrm{z}} / F\left(1 \mathrm{~kg}^{-1}\right)^{\mathrm{c}}$ & $4.21(2.33-15.87)$ & $2.78(1.49-3.38)$ & $-6.68--0.60$ \\
MRT $(\mathrm{h})$ & $25.9(11.2-29.5)$ & $11.3(14.1-24.1)$ & $-8.7-0.5$ \\
Free quinine at $4 \mathrm{~h}(\%)$ & $17(8.4-17.8)$ & - & - \\
\hline
\end{tabular}

Significantly different between patients with chronic liver disease and healthy subjects with: ${ }^{\mathrm{a}} \mathrm{P}=0.016,{ }^{\mathrm{b}} \mathrm{P}=0.001,{ }^{\mathrm{c}} \mathrm{P}=0.013$. 
In patients with malaria, quinine clearance is reduced, although the infection is associated with an increased plasma binding of the drug such that total drug concentrations are elevated, but unbound concentrations remain unchanged [5]. To what extent the pharmacokinetic modification in patients with malaria who also have underlying chronic liver disease would result in the accumulation of plasma unbound quinine concentrations and thus the toxicity cannot be anticipated. This is particularly important when multiple dose regimen of quinine is applied in patients with malaria. Treatment with quinine in these patients who have also concurrent chronic liver disease need special caution with careful ECG monitoring.

\section{References}

1 Hall AP. The treatment of severe falciparum malaria. Trans $R$ Soc Trop Med Hyg 1977; 71: 367-379.

2 Trenholme GM, Williams RL, Rieckmann KH, Frischer H, Carson PE. Quinine disposition during malaria and during induced fever. Clin Pharmacol Ther 1976; 19: 459-567.

3 Brodie BB, Baer HE, Craig LC. Metabolic products of the cinchona alkaloids in human urine. $J$ Biol Chem 1951; 188: $567-581$.

4 Karbwang J, Thanavibul A, Molunto P, Na-Bangchang K. Pharmacokinetics of quinine in hepatitis. $\mathrm{Br} J$ Clin Pharmacol 1993; 35: 444-446.

5 White NJ, Looareesuwan S, Warrell DA, Warrell NJ, Bunnag D, Harinasuta T. Quinine pharmacokinetics and toxicity in cerebral and uncomplicated falciparum malaria. Am J Trop Med Hyg 1982; 73: 564-572.

6 Eastwood GL, Avunduk C. Manual of Gastroenterology. Boston: Little, Brown and Company, 1988.

7 Albani F, Tame MR, De Palma R, Bermardi M. Kinetics of intravenous metoclopramide in patients with hepatic cirrhosis. Eur J Clin Pharmacol 1991; 40: 423-425.

8 Magueur E, Hagege H, Attali P, Singlas E, Etienne JP, Taburet AM. Pharmacokinetics of metoclopramide in patients with liver cirrhosis. Br J Clin Pharmacol 1991; 31: 185-187.

9 Nokhodian A, Santos SRCJ, Kirch W. Digitoxin and its metabolites in patients with liver cirrhosis. Eur $J$ Drug Metab Pharmacokin 1993; 18: 207-213.
10 Child CG. The liver and portal hypertension. Philadelphia: Sauder, 1964

11 Karbwang J, Na-Bangchang $\mathrm{K}$, Molunto $\mathrm{P}$, Bunnag D. Determination of quinine and quinidine in biological fluids by high performance liquid chromatography. Southeast Asian J Trop Med Public Health 1989; 20: 65-69.

12 Silamut K, White NJ, Looareesuwan S, Warrell DA. Binding of quinine to plasma proteins in falciparum malaria. Am J Trop Med Hyg 1985; 34: 681-686.

13 Gibaldi M. Biopharmaceutics and Clinical Pharmacokinetics. Lea \& Febiger Ltd. Fourth Edition. 1991; pp. 14-23.

14 Groszman R, Kotelanski B, Cohn JN, Khati IM. Quantitation of portosystemic shunting from the splenic and mesenteric liver disease. Am J Med 1972; 53: 715-722.

15 White NJ, Karbwang J. Clinical importance of antimalarial pharmacokinetics. Asia Pacific J Pharmacol 1988; 3: 181-189.

16 Berlin CM, Stackman JM, Vessel ES. Quinine-induced alterations in drug disposition. Clin Pharmacol Ther 1975; 18: 670-679.

17 Piafsky KM. Diseases-induced changes in the plasma binding of basic drugs. Clin Pharmacokin 1980; 5: 246-250.

18 Schmid K. Alpha ${ }_{1}$-acid glycoprotein. In The plasma proteins, ed. Putnam TW. New York: Academic Press, 1975: 184-228.

19 Blaschke TF. Protein binding and kinetics of drugs in liver disease. Clin Pharmacokin 1977; 2: 32-34.

20 Kremer JMH, Wilting J, Janssen MH. Drugs binding to human alpha ${ }_{1}$-acid glycoprotein in health and disease. Pharmacol Rev 1988; 40: 1-47.

21 Rothschild MA, Oratz M, Schreiber SS. Serum albumin. Hepatology 1988; 8: 385-401.

22 White NJ, Chantavanich P, Krishna S, Bunch C, Silamut K. Quinine disposition kinetics. Br J Clin Pharmacol 1983; 16: $399-403$.

23 World Health Organization. Advance in malaria chemotherapy. WHO Teach Rep Series 1983; pp. 711.

24 Nosten F, ter Kuile FO, Luxemburger C, et al. Cardiac effects of antimalarial treatment with halofantrine. Lancet 1993; 341: 1054-1056.

25 Hashiba K, Moss AJ, Schwartz PJ. QT prolongation and ventricular arrhythmias. Ann New York Acad Sci 1991; 664 (suppl): 1-24.
(Received 13 February 1995, accepted 4 July 1995) 